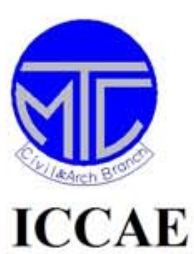

Military Technical College

Kobry Elkobbah,

Cairo, Egypt 7th International Conference

On Civil \& Architecture

Engineering

\title{
INFLUENCE OF NAILS LENGTH ON THE BEHAVIOR OF NAILED- SANDY SOIL SLOPE
}

Mahmoud Hussein Mohamed ${ }^{1}$, El-Sayed A. El-Kasaby ${ }^{2}$, Faeq A. El-Kashef ${ }^{3}$, Abdel Moety H. Heikal', and Emad A. M. Osman. ${ }^{5}$

\section{ABSTRACT}

Soil nailing is a mean of stabilizing earth slope by installing in situ closely spaced steel or plastic bars called nails in the ground. The installation is usually in progressive manner from top to bottom as excavation proceeds. There are many factors that affected the behavior of soil nailing system such as: horizontal and vertical spacing between nails, soil density, length, and method of installation. This research concerns on nail's length, which is one of the most important factors. In this work, three dimensional laboratory model, $1760 \mathrm{~mm} \times 850 \mathrm{~mm} \times 1000 \mathrm{~mm}$, was set up to simulate nailed sandy soil slope of height 7.00 meter with model scale "10". The experimental program was designed and constructed to investigate the behavior of nailed sandy soil slope system with $5.00 \mathrm{~mm}$ in diameter steel bars during, after construction, and under footing pressures at different nails length. The results indicate that increasing nail length up to a length equals to the height of the slope reduces the displacement of the slope face as well as settlement under footing with notable reduction. The system provides an economic, practical and effective method for slope stabilization.

\section{KEY WORDS}

Slope Stabilization, Soil Nailing, Soil Improvement.

\footnotetext{
'-Assistance Researcher, C.R.I, National Water Research Center

2 -Professor of Soil Mechanics and Foundations, Benha University

${ }^{3}$-Professor of Soil Mechanics and Foundation, Minia University

${ }^{4}$-Professor of Soil Mechanics and Foundations, CRI, NWRC.

5 -Professor of Soil Mechanics and Foundation, Minia University
} 


\section{INTRODUCTION}

The fundamental concept of soil nailing consists of reinforcing the ground by passive inclusions, closely spaced, to create in situ a coherent gravity structure and thereby to increase the overall shear strength of the in-situ soil and restrain its displacements considering the ground as a carrying rather than " to be carried " element, $[1,2,4$ \&5]. As the excavation is done from top to the bottom, the soil nails are installed from top downward and a mass of reinforced soil is gradually built up. In order to keep the soils from locally caving in between the bars, some sort of facing need to be installed. This is generally made with shotcrete reinforced by a welded wire mesh, [3, $6,8 \& 9]$. This paper investigates the behavior of soil slope nailing system during and after construction, and under footing pressures using different nail lengths. A laboratory physical model was used to get a complete picture on the effect of nails length on the behavior of the system.

\section{EXPERIMENTAL WORK}

\section{- Laboratory Model}

A three dimensional model was built up to simulate a soil nailed slope of height 7.00 meter with model scale "10". The study model comprises an open frontal Perspex box $1760 \mathrm{~mm} \times 850 \mathrm{~mm} \times 1000 \mathrm{~mm}$, Fig. (1) and the box contains the nailed slope of $2250 \mathrm{~kg}$ of dry sand with properties shown in Table (1) and steel bars nails of 5.00 $\mathrm{mm}$ in diameter. The face consists of strips of Perspex strips, $5.00 \mathrm{~mm}$ thick. Steel rigid plate of dimensions $840 \mathrm{~mm} \times 150 \mathrm{~mm} \times 22 \mathrm{~mm}$ thick was used as a footing to give a distributed load on the soil. The sand bed in the model was formed using automatic sand raining system in order to control the density. In all testes the horizontal and vertical spacing Sh and Sv between nails are equal to $0.4 \mathrm{H}$ where $\mathrm{H}$ is the slope height, [7].

\section{- Instrumentation}

A number of 108 foil strain gauges type (KFG - 5 - 120 - C1 - 11 L1M2R) manufactured by KYOWA - JAPAN with grid length $5.0 \mathrm{~mm}$ and grid width $1.4 \mathrm{~mm}, 3$ dial gauges with accuracy of $0.01 \mathrm{~mm}$, and 2 LVDs of capacity $100 \mathrm{~mm}$ and rated out put $2.5 \mu \mathrm{V} / \mathrm{V} \pm 0.2 \%$ with sensitivity $50 \times 10^{-8} / \mathrm{mm}$ were used to monitor the behavior of soil nailed slope during and after construction under various uniform footing pressure. Positions of these devices are shown in Fig. (2), [7].

This study shed much more light on the effect of the nails length on the force mobilized in the nail, horizontal displacement of the slope, settlement of the footing and the earth pressure at the slope face, under and behind the soil mass taking into account construction procedures as well as loading stages.

\section{RESULTS AND DISCUSSION}

\section{Lateral Movement of the Soil Nailing Slope}


The lateral displacement of the nailed slope facing were recorded with 3 dial gauges at three measurements points $A, B$ and $C$ at distances $Z=70,350$, and $630 \mathrm{~mm}$ from the top surface. These distances are expressed as $0.1 \mathrm{H}, 0.5 \mathrm{H}$, and $0.9 \mathrm{H}$. The facing movements were recorded after each excavation stage, i.e. during construction, until the excavation was completed. Then, the footing was loaded incrementally with pressure of $5.0,10.0,20.0$, and $30.0 \mathrm{kPa}$. Readings of the displacement (D) were measured after each increment, i.e. after construction. Lateral movement of the slope face of the nailing slope during construction and loading stages are shown in Fig. (3a, b, c, d, and e).

These figures were obtained from model tests for cases of no nails and with nails having different lengths. From these figures, it can be seen that:-

- Generally, the movement in the middle third is bigger than the top and bottom third.

- For all cases (construction and loading stages), the lower third of the slope has the minimum horizontal displacement.

- The maximum displacement at construction stages occurred at the upper third of the slope in case of nail length $1.00 \mathrm{H}$ and $1.20 \mathrm{H}$, whereas in case without nails or using nails of length $0.50 \mathrm{H}$ and $0.75 \mathrm{H}$, the maximum horizontal movement was at the middle third of the slope.

- The maximum displacement at loading stages occurred at the middle third of the slope except when using nail length of $1.20 \mathrm{H}$ at which the maximum horizontal movement was at the upper third of the slope.

Fig. (4) shows the relation between the nail length and horizontal movement at different nail length (at point (B), Fig. (2) as an example). It is clear that, in general the presence of nails decrease the lateral movement. This due to installation of nails mobilize friction stresses between the around sand and the surface of nail. This friction stresses prevent or decrease the lateral movement. By increasing the length of nail, the chance and the total value of shear stresses between sand and nail increase and hence the lateral movement decreases rapidly when the nail length increases from $0.3 \mathrm{H}$ to $0.75 \mathrm{H}$ but when the nail length increases from $0.75 \mathrm{H}$ to $1.00 \mathrm{H}$ the lateral movement decreasing is slight and almost none when the length is $1.2 \mathrm{H}$. This may be due to increasing the nail length is very effective up to certain limit, i.e. when the length lies in a stable zone (behind the surface of failure) so that any increase has introduced nothing to the stability of soil mass.

\section{Settlement of the Footing}

The foundation settlements were measured at three points on the footing and then the average value was presented. The footing settlements were measured by means of three LVDTs. the footing settlements were measured at each surcharge load increment after reaching the slope height. Fig. (5) presented the footing settlement ratio $(\mathrm{S} / \mathrm{H})$, i.e. vertical settlement/ slope height, for different nails length at different footing pressures. From this figure, it can be seen that: the footing settlement decreases as the nail length increases by percentages range from $12.12 \%$ to $50.94 \%$. This could be attributed to the fact that the lateral displacement of the facing slope decreases when the nail length increases, consequently the footing settlement will decrease too. That is meaning that the soil nailing system can sustain more footing load with no failure. 


\section{Force in the Nail}

The axial strains in the nails were measured by means of electrical resistance strain gauges. The instrumented nails were distributed in the center of the soil-nailed mass, one in the upper third, one in the middle, and one in the lower third. Each nail was instrumented with strain gauges on its upper and lower faces at different locations along its whole length. These enable axial strains to be measured through strain meter connected to the strain gauges, from which the axial force distribution along the nail could be obtained. The strains induced in the nails were measured during excavation process as well as at each footing load increment. The distribution of tensile forces induced along the nails against nails length during excavation stages and after loading stages is shown in Fig. (6a, b, c, d, e, f, g and h). From these figures, it can be seen that:

- In all cases, the distribution is non-uniform and all the forces are tensile.

- The minimum tensile force occurs at the end of the nails in all cases whereas the maximum tensile force is at the middle third of the nail.

- The tensile force increases as the excavation is progressing then as the surcharge increases.

Figures ( $7 a$ and $b)$ present the effect of nails length on the maximum tensile force in the nails at different levels. From these figures, it is clear that generally, as the lengths increases the tensile force increases in construction stages and loading stages. It is also clear that the lower nails have less tensile force than the upper nails but the middle nails have the maximum tensile force in both construction and loading stages. This is may be due to the maximum horizontal displacements were at mid height of the slope. Hence, the tensile force mobilized in the nail increases because the friction stresses between the nail and the sand and reaches its maximum value. In case of loading stage, Figure (7b), increasing the nails length results in increasing the maximum tensile forces in the nail, particularly at the middle nail. The relation is linear but in the other nails the relationship take a concave shape, i.e. it decreases by increasing the length of the nail up to nail length of $0.75 \mathrm{H}$ and then the maximum tensile force goes up with increasing the nail length. This may be due to during loading stages there are some disturbance of the soil under the footing and around the nail, particularly the nails near the top and bottom (excavation and construction) but the middle there is soil expansion only.

\section{CONCLUSIONS}

The maximum horizontal displacement at construction stages occurred at the higher third of the slope in case of long nails whereas in case of short nails, the maximum horizontal displacement was at the middle third of the slope. Settlement of the surface of slope (ground surface) was occurred during construction stages and increased by increasing the footing pressure. The distribution of tensile force exerts in nail was non-linear. It approaches to the zero at ends of the nail and increases toward the middle third of the nail. It reaches its maximum value at middle third of the nail during excavation progress and then with loading increasing. There was reduction in slope facing displacement due to the increases of nails length until length of $(1.00 \mathrm{H})$ where $\mathrm{H}$ is the slope height by a ratio ranged from $5.12 \%$ to $90.37 \%$. There was reduction in footing settlement due to the increases of nails 
length until length of $(1.00 \mathrm{H})$ by a ratio ranged from $12.20 \%$ to $50.94 \%$. Increasing the nails length leads to increasing the maximum tensile force exerted in the nail.

\section{REFERENCES}

1) Byrne, R. J., D. Cotton, J. Porterfield, C. Wolschlag, and G. Ueblacker "Manual for Design \& Construction Monitoring of Soil Nail Wall." Publication No. FHWA-SA-96-069R, USA. (1998).

2) CLOUTERRE French National Research Project, 1991, Recommendations, English translation." FHWA, July, USA. (1993).

3) Hamouda, A. A. "Behavior of Nailed-Slopes in Sand Soil Due to Neighboring Foundation." A thesis is Submitted to the Faculty of Engineering, Cairo University in Partial fulfillment of Requirement for the Degree of Doctor of Philosophy, Egypt. (2001).

4) Juran, I., and V. Elias "Ground Anchors and Soil Nails in Retaining Structures." Chapter 26,Foundation Engineering Handbook. Edited by HSAI-YANG FANG, Second Edition, Chapman \& Hall, USA. (1991).

5) Lee, C. K., and S. K. Jeon "Analysis of Wall Displacement and Tensile Force of Soil Nailed Systems in Ground Excavations." Proceedings of the Fifteenth International Conference on Soil Mechanics and Geotechnical Engineering, Vol. 3, August, Istanbul. (2001).

6) Li, J., L. G. Tham, S. M. Junaideen, Z. Q. Yue, and C. F. Lee "Loose Fill Slope Stabilization with Soil Nails." Journal of Geotechnical and Geoenvironmental Engineering, Vol. 134, Issue 3, March, New York, USA. (2008).

7) Mahmoud Hussein, "Soil Nailing System as Ground Improvement" $A$ Thesis is Submitted to the Faculty of Engineering, Minia University in Partial fulfillment of Requirement for the Degree of Doctor of Philosophy, Egypt. (2008).

8) Salama, M. E., E. J. Cording, and J. H. Long "Parametric Study for Factors Which Influence the Behavior of Nailed-Soil Retaining Walls." Proceedings of the Second International Conference on Engineering Research, Vol. II, December, Port Said, Egypt. (1995).

9) Salama, M. E., E. J. Cording, and J. H. Long "Analysis of Soil Nailed Retaining Walls." Proceedings of Eleventh African Regional Conference on Soil Mechanics and Foundation Engineering, Vol. 2, December, Cairo, Egypt. (1995). 
Proceedings of the 7 th ICCAE Conf. 27 -29 May, 2008

Table 1. Summary of the Properties of Using Sand

\begin{tabular}{|c|c|c|c|}
\hline Property & Value & Property & Value \\
\hline$\%$ of Clay & 0.00 & Specific gravity $\left(G_{s}\right)$ & 2.62 \\
\hline$\%$ of Silt & 1.33 & $\begin{array}{c}\text { Minimum unit weight } \\
\left(\gamma_{\min }\right)\left(k N / \mathrm{m}^{3}\right)\end{array}$ & 15.30 \\
\hline$\%$ of fine Sand & 39.17 & $\begin{array}{l}\text { Maximum unit weight } \\
\left(\gamma_{\max }\right)\left(\mathrm{kN} / \mathrm{m}^{3}\right)\end{array}$ & 17.80 \\
\hline$\%$ of medium Sand & 58.63 & Minimum void ratio $\left(e_{\min }\right)$ & 0.472 \\
\hline$\%$ of coarse Sand & 0.87 & Maximum void ratio $\left(e_{\max }\right)$ & 0.712 \\
\hline$\%$ of fine Gravel & 0.00 & Relative Density $\left(D_{r}\right)(\%)$ & 48 \\
\hline Effective diameter $\left(D_{10}\right) \mathrm{mm}$ & 0.126 & Angel of internal friction $(\phi)^{\circ}$ & 34 \\
\hline Coefficient of uniformity $\left(C_{u}\right)$ & 1.99 & Unit weight $\left(\gamma_{b}\right)\left(k N / m^{3}\right)$ & 16.41 \\
\hline Coefficient of gradation $\left(C_{u}\right)$ & 1.00 & Void ratio (e) & 0.597 \\
\hline
\end{tabular}

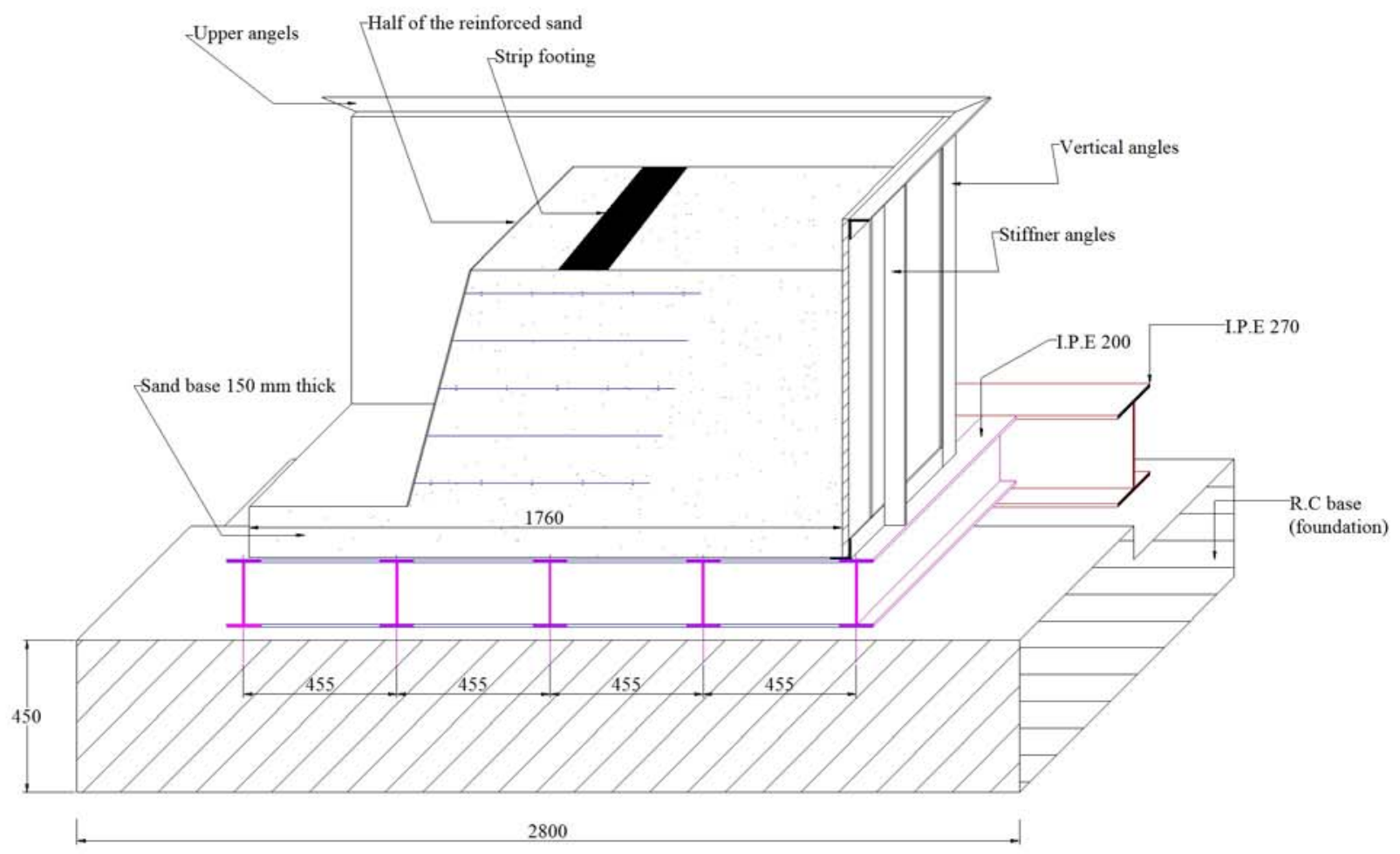

Fig. 1. Sand bed 

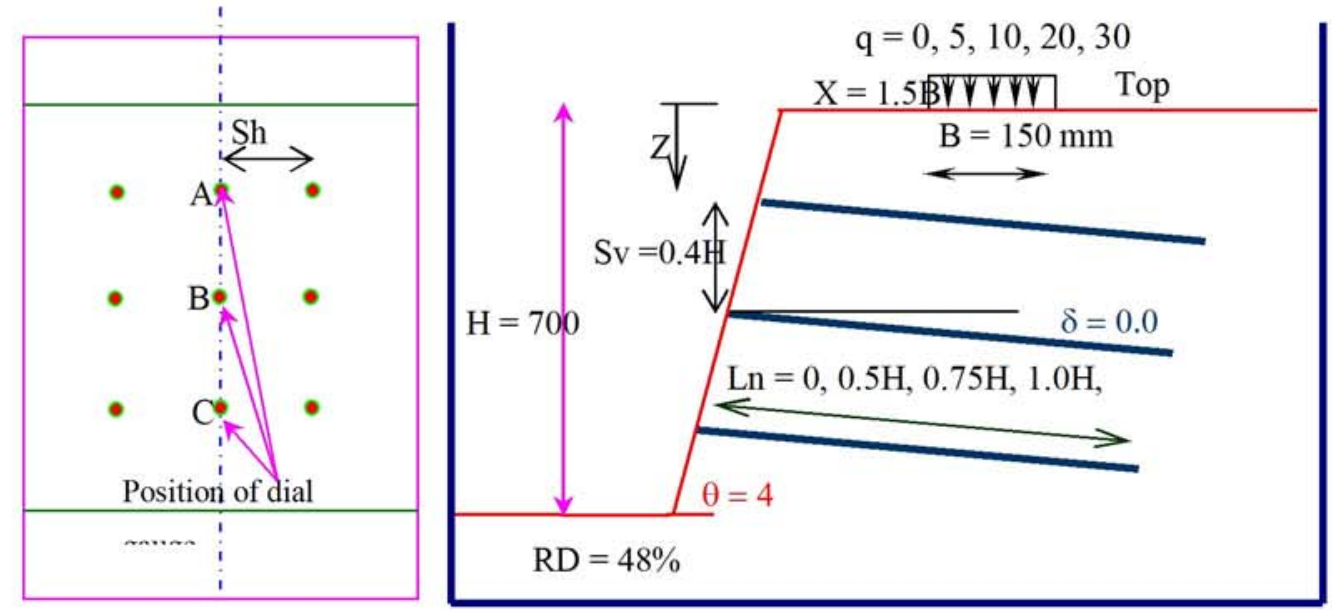

Fig.2. Physical model
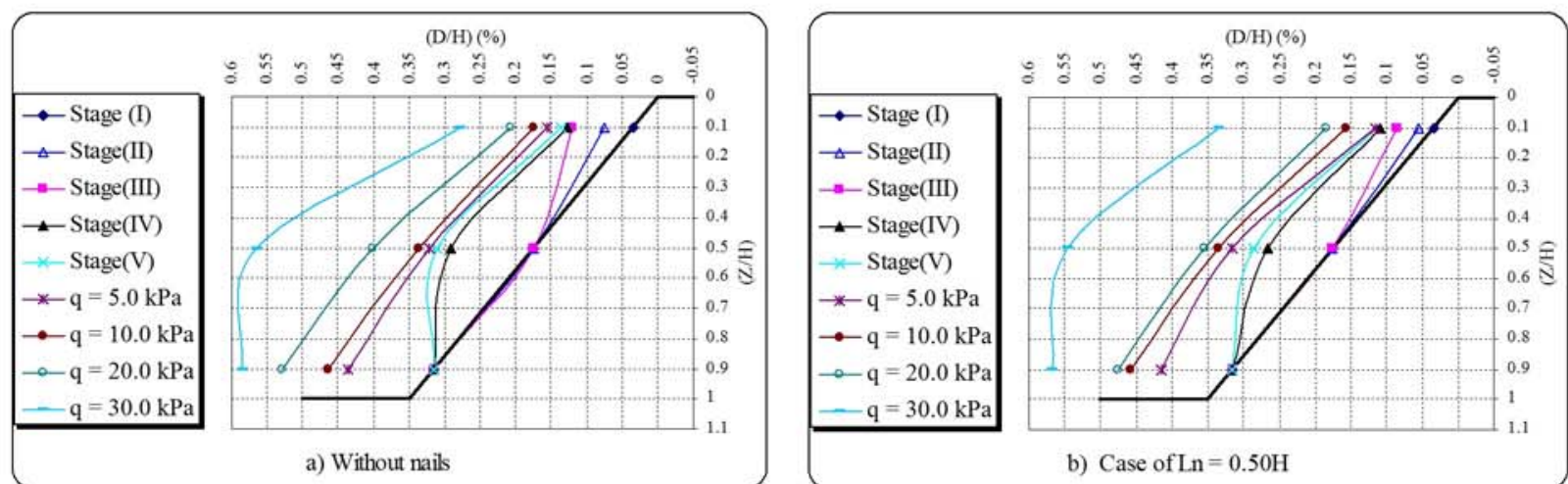

a) Without nail

b) Case of $\mathrm{Ln}=0.50 \mathrm{H}$
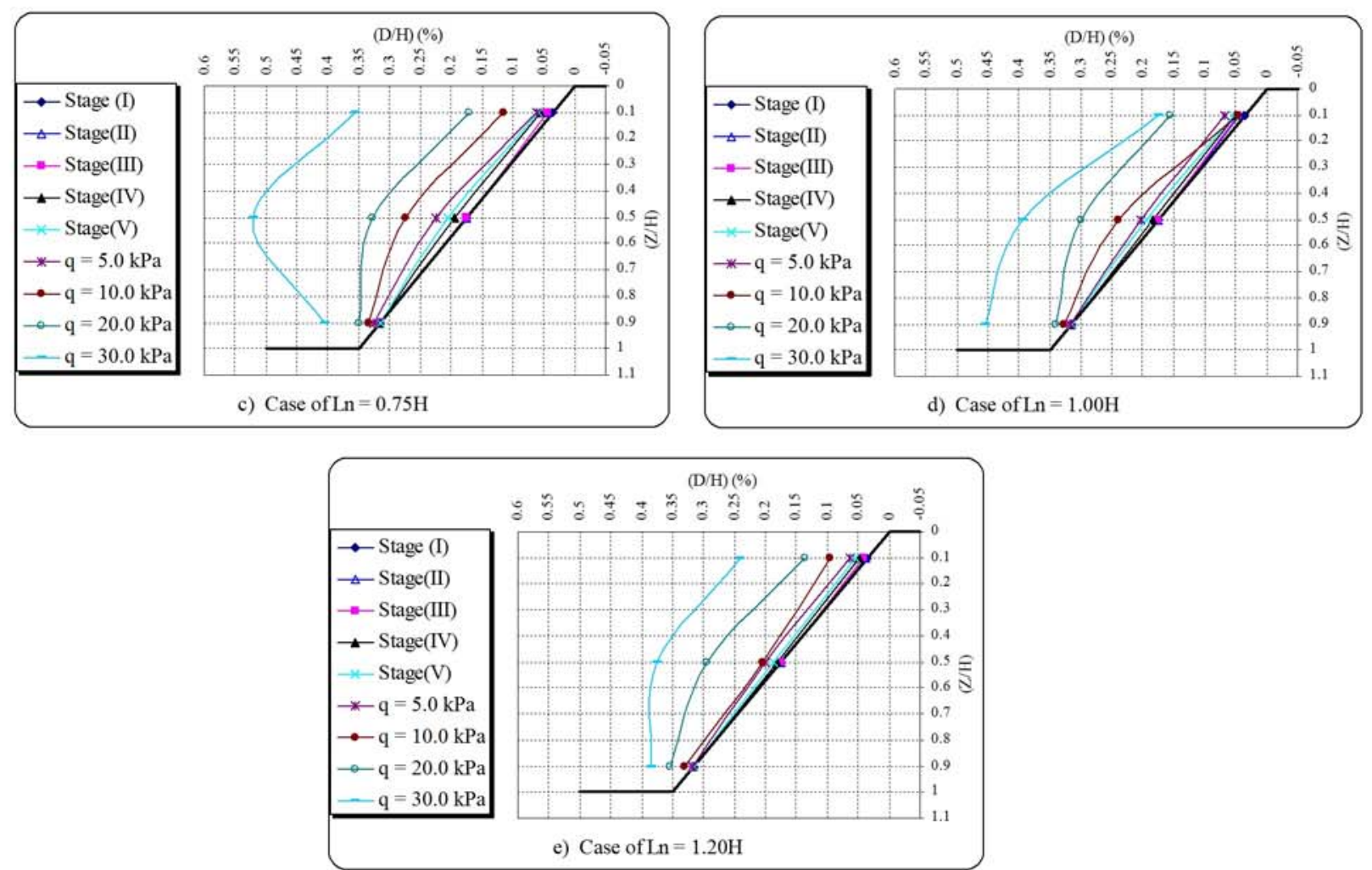

Fig.3. Lateral movement of the slope at different nails length 


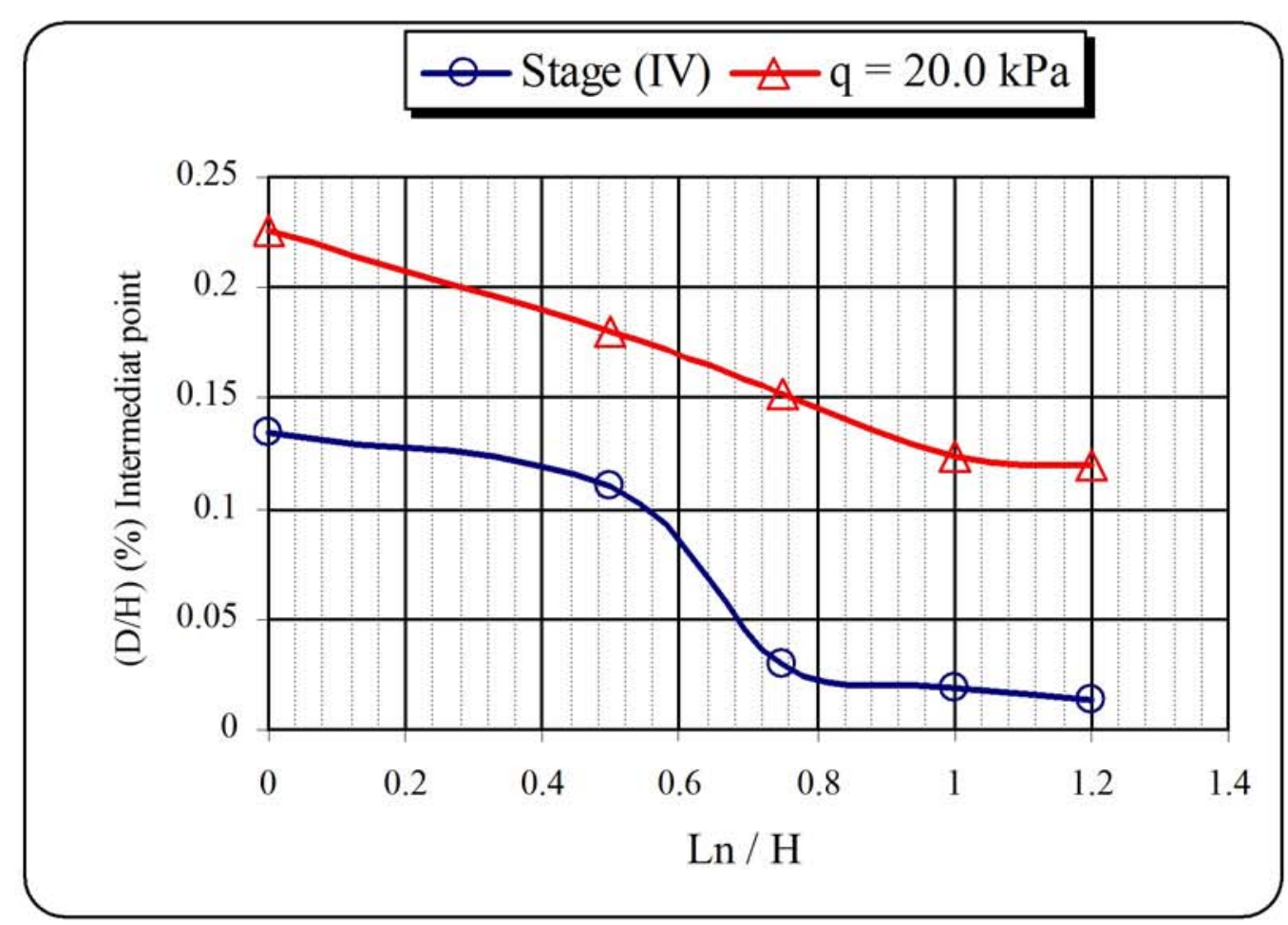

Fig.4. Effect of nail length on the horizontal movement of middle measured point (B)

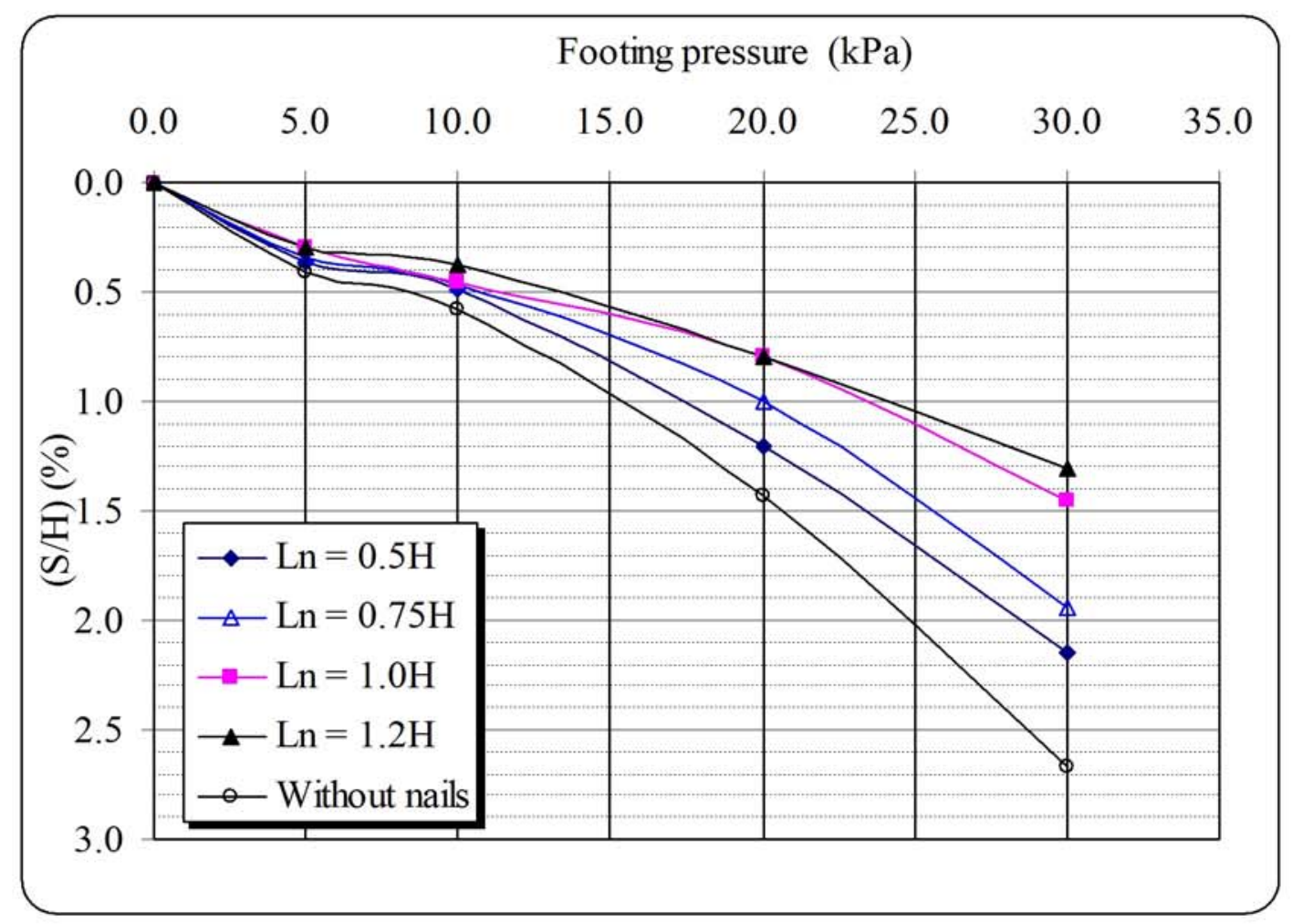

Fig.5. Effect of nails length on the settlement of the footing 

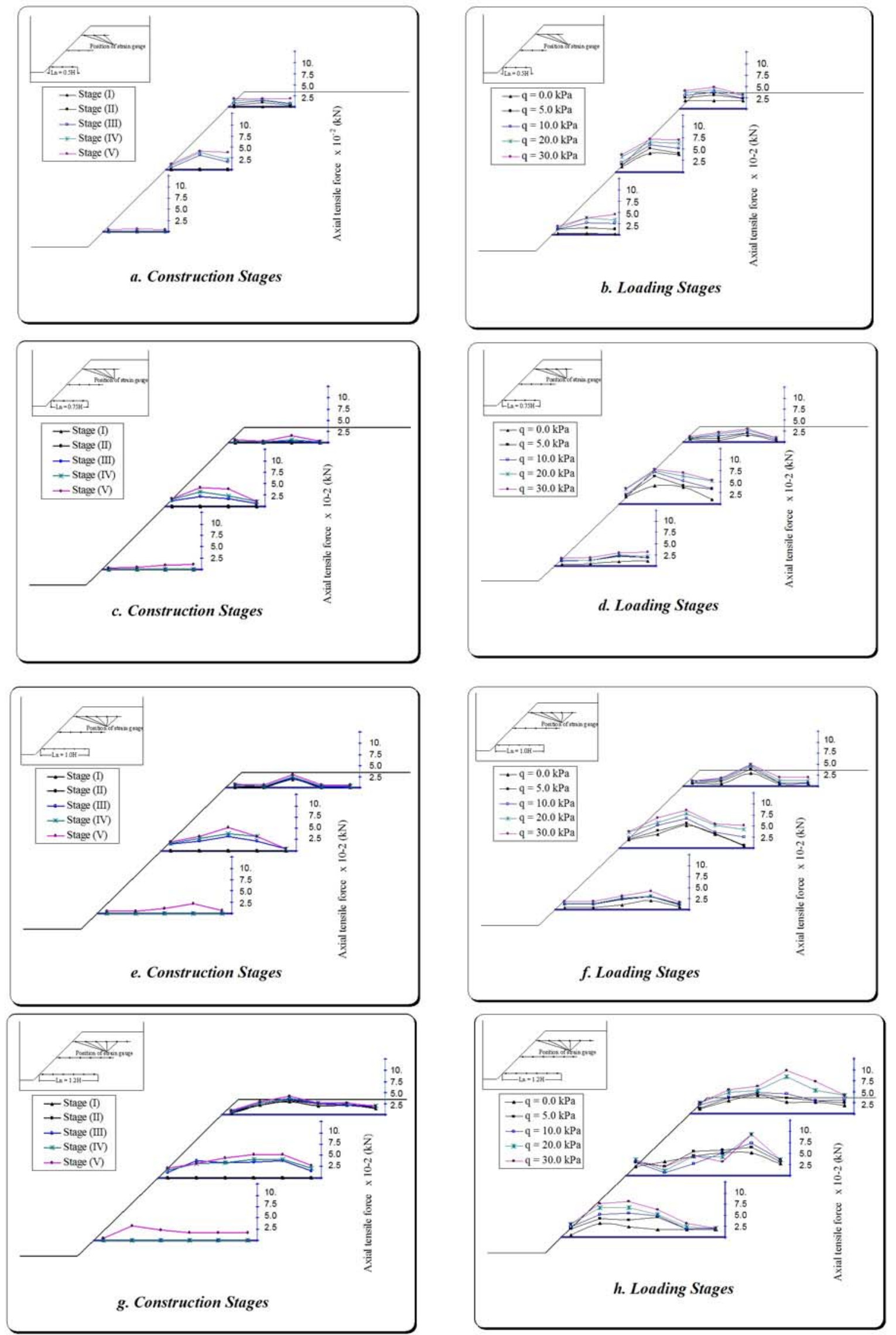

Fig.6. Distribution of the nail force at different levels and nails length 

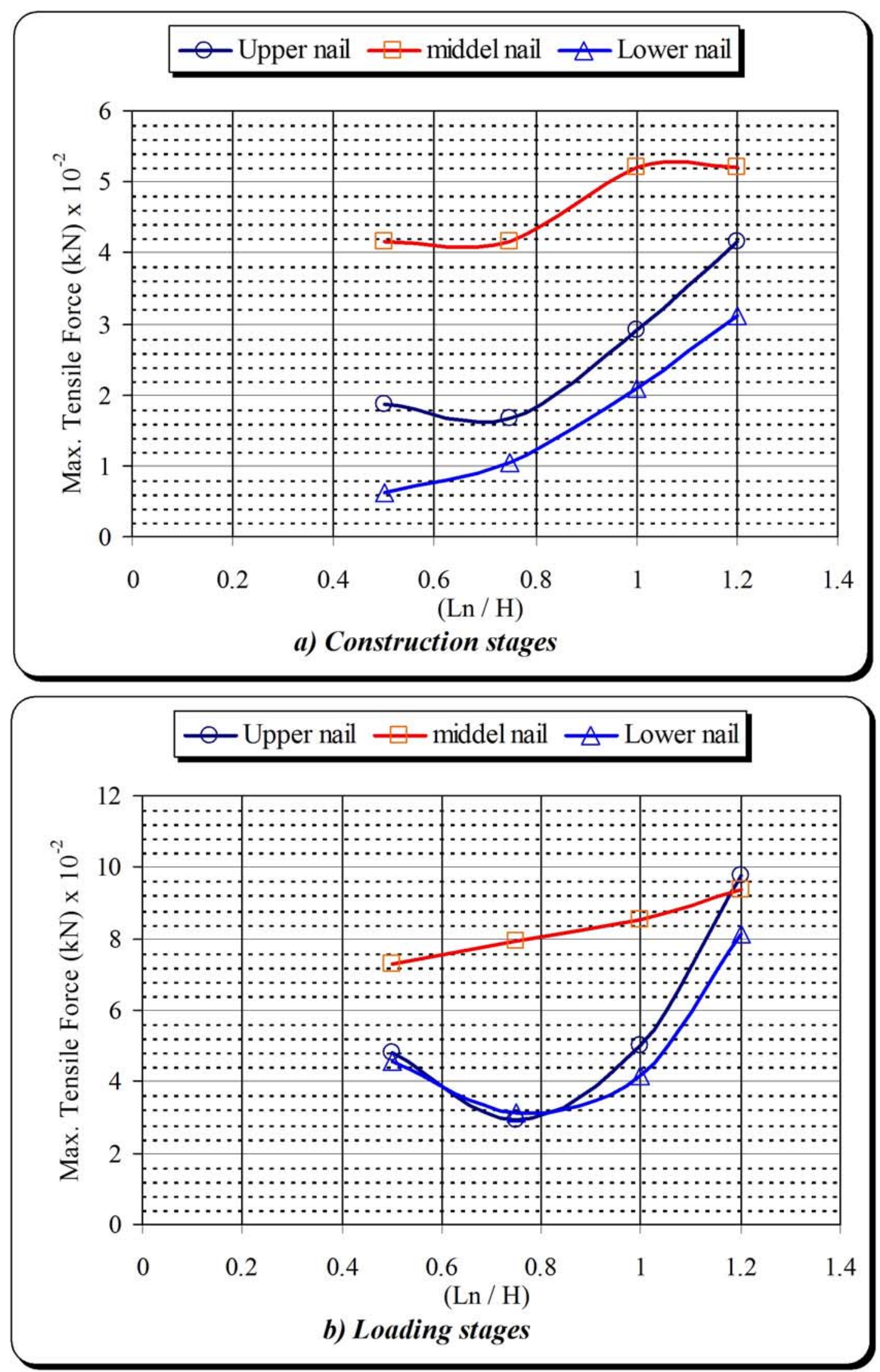

Fig.7. Effect of nails length on maximum tensile force in the nail at different levels 